\title{
EDITORIAL
}

\section{LA CRISIS Y SUS SIGNIFICADOS}

Los últimos meses de este año 2008 han marcado la existencia de una crisis económica mundial, que ha requerido la construcción de planes de ajuste, un reestudio de las políticas de inversión, una revisión del consumo y una desaceleración de ciertas actividades. La crisis ha tenido injerencia en nuestro modelo y se prevé que el año 2009 presentará frentes complejos asociados con esa realidad en el mundo laboral, previsional, de seguros, etc.

El Derecho, sin duda, no es indiferente a este tipo de situaciones. Si bien la generación de las normas, las decisiones de los tribunales, la jurisprudencia constitucional, por mencionar algunos, no reaccionan con la celeridad con que los medios de comunicación dan a conocer la caída de ciertos grupos empresariales o las dificultades del sistema financiero, las realidades sociales impregnan también al mundo jurídico y de alguna manera representan el trasfondo de ciertas conductas, que se pueden desarrollar asociadas con la crisis, con ocasión de la crisis o con la justificación de la crisis, y que van desde elementos tan positivos como el ahorro y la reducción del gasto a situaciones que faltan a la ética como asimismo al Derecho, cuyo es el caso de la corrupción, del abuso laboral, del alza desmedida de precios o de la falta de servicio por parte de la Administración.

Sin embargo, no es esa nuestra única preocupación, pues, independientemente de las consecuencias que para nuestro mundo jurídico tenga la retracción económica ya instalada o que se aproxima, según el país, la cual es motivo de preocupación y de alerta en sí, vivimos también paralelamente otras crisis con connotación jurídica que debieran alarmarnos del mismo modo.

En efecto, en el lapso de muy pocos meses estamos presenciando, solo para enumerar algunos casos que nuestros lectores siguen en las noticias del día, cientos de exámenes o de análisis de muestras con resultado de VIH positivo y de hepatitis $\mathrm{C}$ no notificados a quienes los padecen -lo cual, obviamente, no infiere tan solo en las políticas ministeriales de manejo de situaciones epidemiológicas, sino que representa un daño considerable al derecho a la protección de la salud de los afectados-, suicidios de adolescentes que han sido posibles víctimas de bullying escolar o de abuso sexual cometido entre compañeros -una demostración de la indiferencia con que el sistema se ocupó de sus casos y de las consecuencias de las situaciones vividas-, eventual utilización de sicarios en crímenes y delitos contra las personas -lo que, obviamente, implica una creciente profesionalización de la criminalidad con las funestas consecuencias que ha tenido en países vecinos-, y posibles situaciones de maltrato animal en instituciones que han recibido fondos para su cuidado, lo que afecta la fe pública y horroriza a una sociedad que ha tomado conciencia que el respeto por los animales dignifica a las personas que así lo entienden. 
Nada de lo mencionado puede imputarse a la crisis económica, a la baja de las acciones o al desempleo, pero colabora activamente en que el ciudadano medio empiece a tener una impresión transversal de crisis que no es buena ni para la situación psicológica de los chilenos ni para la operación correcta de nuestras instituciones.

Es indispensable, por ello, exigir de los entes jurisdiccionales más severidad en el análisis de casos; de la Administración, cadenas de controles efectivos; de la red social una solidaridad práctica y no solo teórica, y de la comunidad una actitud de acogimiento con las víctimas, evitando la estigmatización y exclusión tan propias de quienes no visualizan la universalidad de los problemas y del dolor humanos.

Si hemos sido capaces de ratificar hace pocos meses la Convención de los derechos de las personas con discapacidad y su protocolo facultativo; si podemos conmovernos con el testimonio de una mujer que vivió varios años secuestrada en su propio país; si se condena públicamente las situaciones de violencia intrafamiliar y el abandono de menores, demostraciones que para nuestra sociedad el Derecho -con mayúsculas- es en realidad una compleja malla de actitudes, de toma de conciencia y de protección de la persona humana, no cabe la indiferencia frente a las situaciones negativas que estamos viviendo, que repugnan a esas mismas concepciones y que no pueden ocultarse o justificarse en crisis actuales o venideras.

La única crisis de la que no podremos salir será la instalación de la complacencia y la invisibilidad del abuso, de la irresponsabilidad y de la ineficiencia.

Todo el equipo de la Revista Chilena de Derecho desea a nuestros lectores y a los autores que generosamente nos han acompañado a lo largo del año, unas hermosas fiestas y un 2009 en el que, más allá de las dificultades, rescatemos lo trascendente: el valor de la persona y la unidad de todos los chilenos.

Ángela ViVANCo MarTíneZ

Directora

Revista Chilena de Derecho 